\title{
The effects of preexposure to a warning or a safety signal on the acquisition of a two-way avoidance response in rats
}

\author{
MAURICE A. FELDMAN \\ McMaster University, Hamilton, Ontario, Canada
}

\begin{abstract}
Rats that were given nonreinforced preexposure to either a warning signal or a safety signal were significantly retarded in the subsequent learning of a two-way shock-avoidance response compared to rats that were not preexposed. These results are consistent with Mackintosh's "learnedirrelevance" formulation of latent inhibition. They do not support a prediction derived from an extension of Kalat and Rozin's "learned-safety" hypothesis. These findings suggest that preexposures in the total absence of aversive events do not endow a stimulus with safety properties.
\end{abstract}

The term, "latent inhibition" (Lubow, 1965) refers to the deleterious effect of prior nonreinforced exposure to the conditioned stimulus (CS) on subsequent conditioning. Despite the many empirical demonstrations of the phenomenon (Lubow, 1973), there is still no adequate theoretical account of the effect. There are, however, a number of hypotheses. They range from the proposition that incompatible responses are conditioned to the CS during preexposure (Ackil \& Mellgren, 1968; Lubow, 1965; Lubow \& Moore, 1959; Siegel, 1969) to the suggestion that the animal fails to attend to the preexposed stimulus (Halgren, 1974; Lubow, 1965; Reiss \& Wagner, 1972).

Recently, Kalat and Rozin (1973) have proposed a "learned safety" hypothesis which they say can account both for the latent inhibition and the longdelay effects observed in taste-aversion learning. According to this "learned-safety" hypothesis, the rat actively learns that a preexposed taste does not lead to aversive consequences (i.e., toxicosis), and this retards subsequent association of this "safe" taste with toxicosis.

Although Kalat and Rozin's (1973) hypothesis was designed to explain phenomena of poisonavoidance learning, it may also be applicable as an account of latent inhibition effects with a variety of exteroceptive conditioned and unconditioned stimuli.

A version of this paper was presented at the annual meeting of the Canadian Psychological Association, Quebec City, June 1975. This research was supported by Research Grant APA-0298 to Dr. S. Siegel from the National Research Council of Canada. The author is grateful to Dr. Siegel for his advice and assistance throughout all phases of this work, and to Drs. A. H. Black, C. Crowell, and R. B. Cormier for their comments on earlier versions of this paper. The advice and support of Riley Hinson are also appreciated. Reprints may be obtained from the author, who is now at the Department of Psychology, Southwestern Regional Centre, P.O. Box 1000, Blenheim, Ontario, Canada NOP IAO.
Indeed, as Siegel (1974) has noted, preexposure to taste and to other exteroceptive CSs produce similar effects and share a number of characteristics. The generalization proposed here is that any stimulus will become a "safe" stimulus if preexposed in the absence of aversive events.

The evidence for a learned-safety account is equivocal. Kalat and Rozin (1973) and Siegel (1974) present evidence in favor; however, Rescorla (1971, Experiment 2), in fear conditioning, and Best (1975), in taste-aversion learning, find that preexposing a stimulus disrupts learning that the familiar stimulus predicts the absence of aversive events. These last two studies cast some doubt on the learned-safety formulation.

Mackintosh (1973) has proposed an alternative "learned-irrelevance" hypothesis of latent inhibition which states that the animal learns to ignore the preexposed stimulus. This results in a reduction in the ability of that stimulus to enter into subsequent associations without the stimulus developing active inhibitory properties. Reiss and Wagner (1972) and Rescorla (1971) have presented evidence in support of this analysis. They have shown that, while preexposure retards acquisition, the preexposed stimulus does not acquire the capacity to actively inhibit responses to an excitatory CS when the two stimuli are compounded in a summation test. Kremer (1972), however, has presented data directly contrary to the findings of Reiss and Wagner (1972) and Rescorla (1971).

The purpose of the present study was to test the relative merits of the extension of learned-safety vs. learned irrelevance in accounting for the strong latent inhibition effect observed (Ackil \& Mellgren, 1968; Ackil, Mellgren, Halgren, \& Frommer, 1969) in two-way shock-avoidance learning.

In this experiment, one stimulus, the warning signal, predicted the occurrence of shock. A second 
stimulus, the safety signal, was presented following escape and avoidance responses and signaled an intertrial interval free from shock. Recent evidence (e.g., Bolles \& Grossen, 1969) indicates that a safety signal can serve as an effective reinforcer of avoidance behavior.

According to the extended learned-safety hypothesis proposed here, if a stimulus gains safety properties through preexposure, acquisition of avoidance responses should be retarded if that stimulus is then used as a warning signal. If the preexposed stimulus instead is used explicitly as a safety signal, however, avoidance acquisition should be facilitated or at least not disrupted. The preexposed stimulus should be an effective reinforcer of avoidance behavior from the onset of avoidance training.

The learned-irrelevance hypothesis, on the other hand, would predict that preexposing either the warning signal or the safety signal will retard subsequent avoidance acquisition. According to this hypothesis, preexposure reduces the ability of a stimulus to enter into any association, regardless of whether that association involves predicting the presence or absence of the unconditioned stimulus.

Both the learned-safety and learned-irrelevance positions state that preexposing the warning signal should retard subsequent avoidance acquisition. Learned irrelevance predicts that preexposing the safety signal should also retard avoidance conditioning. Learned safety predicts that preexposing a safety signal should not interfere with avoidance conditioning and perhaps should facilitate avoidance acquisition.

\section{METHOD}

\section{Subjects}

Subjects were male albino, Charles River rats, weighing 275-325 g and obtained from Canadian Breeding Farms, Quebec, Canada. Each rat was housed in its own cage with food and water freely available.

\footnotetext{
Apparatus

The experimental apparatus consisted of a Lehigh Valley Electronics automated two-compartment, toggle-floor shuttlebox (Model 146-04) housed in a sound-attenuating chamber. The unconditioned stimulus was a $.5-\mathrm{mA}$ electric shock delivered by a Grason-Stadler shocker-scrambler (Model E1064 GS) to the pivoted grid floor of the shuttlebox. A $7.62-\mathrm{cm}$ metal (nonelectrified) barrier separated the shuttlebox into two identical compartments. The warning signal was a $1,000-\mathrm{Hz}$ tone at $85 \mathrm{~dB}$ presented through a $6.35-\mathrm{cm}, 4-\mathrm{ohm}$ speaker located in the middle of the roof of the shuttlebox. Two additional speakers recessed into each side wall of the sound-attenuating chamber delivered constant white background noise at $70 \mathrm{~dB}$ from a Grason-Stadler white-noise generator (Model 901A). Light stimuli which served as the safety signal were provided by the simultaneous onset of a 6-W light bulb mounted on the roof of the sound-attenuating enclosure and the two cue lights located $12.70 \mathrm{~cm}$ above the grid floor in the center of each end wall of the shuttlebox. Responses were monitored by a microswitch which was triggered whenever the rat moved from one compartment to the other displacing the pivoted grid floor. Standard relay and recording equipment were used to program stimulus events and record responses.
}

\section{Procedure}

Each rat was run in one session, which consisted of two phases: 100 preexposure trials followed immediately by 200 avoidance training trials. Total session time was approximately $51 / 2 \mathrm{~h}$. Subjects were randomly assigned to one of four groups. Four rats were discarded because they perched on the metal barrier during avoidance training, and two additional rats were discarded because of apparatus failures. These six rats were replaced with naive rats until each of the four groups described below had a total of 10 subjects:

$P E-W S$ (preexposed to the warning signal). This group was placed in the shuttlebox and given 100 preexposures to a $5-\mathrm{sec}$ 85-dB tone which served as the warning signal (WS) in subsequent avoidance training. During the preexposure phase, the interstimulus interval averaged $60 \mathrm{sec}$ (range: $30-90 \mathrm{sec}$ ). Shuttle responses during preexposure trials had no programmed effect on the presentation or termination of the stimulus. Following the last preexposure trial, the avoidance training phase was initiated. Each trial in this phase of the experiment started with the onset of the tone WS. If the rat failed to move from one compartment to the other during the first $5 \mathrm{sec}$ of the WS, a continuous .5-mA shock was delivered to the rat via the grid floor. The WS and shock remained on until a shuttle response was made, and then the shock was terminated immediately; the WS, however, remained on for an additional $5 \mathrm{sec}$, during which the "lights on" safety signal (SS) was presented. Five seconds following the response, the WS and SS both were terminated. If the rat shuttled to the other compartment during the first $5 \mathrm{sec}$ of the WS, shock was avoided; the WS remained on and was accompanied by the SS during the 5-sec interval following the avoidance response.

This procedure, in which the WS remained on for $5 \mathrm{sec}$ following escape and avoidance responses, was adopted for two reasons. First, it insured that the onset of the SS would be the only stimulus reliably following successful escape or avoidance performance. (If the WS terminated immediately following a response, its termination could have become the relevant safety signal for the rat). Second, it was thought that the presence of the excitatory WS during the presentation of the SS would optimize the conditioning of inhibitory or safety properties of the SS (cf. Best, 1975). Additional responses during the 5 -sec safety signal period had no effect on stimulus events. Training was carried out in darkness (except when the "lights-on" SS was presented) with an intertrial interval continuing to average $60 \mathrm{sec}$.

$P E-S S$ (preexposed to the safety signal). This group received preexposure and avoidance training similar to the PE-WS group, but preexposure consisted of 1005 -sec presentations of the "lightson" SS.

$N P E$ (nonpreexposed with safety signal during avoidance training). This group spent the same period of time in the darkened shuttlebox $(108.33 \mathrm{~min})$ as the two preexposed groups prior to avoidance training. Subjects in this group, however, were not preexposed to either the WS or the SS used in subsequent avoidance conditioning.

NPE (NO SS) (nonpreexposed with no safety signal during avoidance training). This group also spent $108.33 \mathrm{~min}$ in the darkened shuttlebox before avoidance training with neither the WS nor the SS presented. During avoidance training, only the WS was presented. It remained on for an additional $5 \mathrm{sec}$ following responses but no other stimulus was presented. This group was included to assess the significance of the SS contingency in the other three groups.

\section{RESULTS}

Figure 1 presents the mean percent avoidance responses in successive blocks of 20 trials for the four groups. As indicated in Figure 1, avoidance learning in the two preexposed groups (PE-WS and PE-SS) and in the nonpreexposed group without 


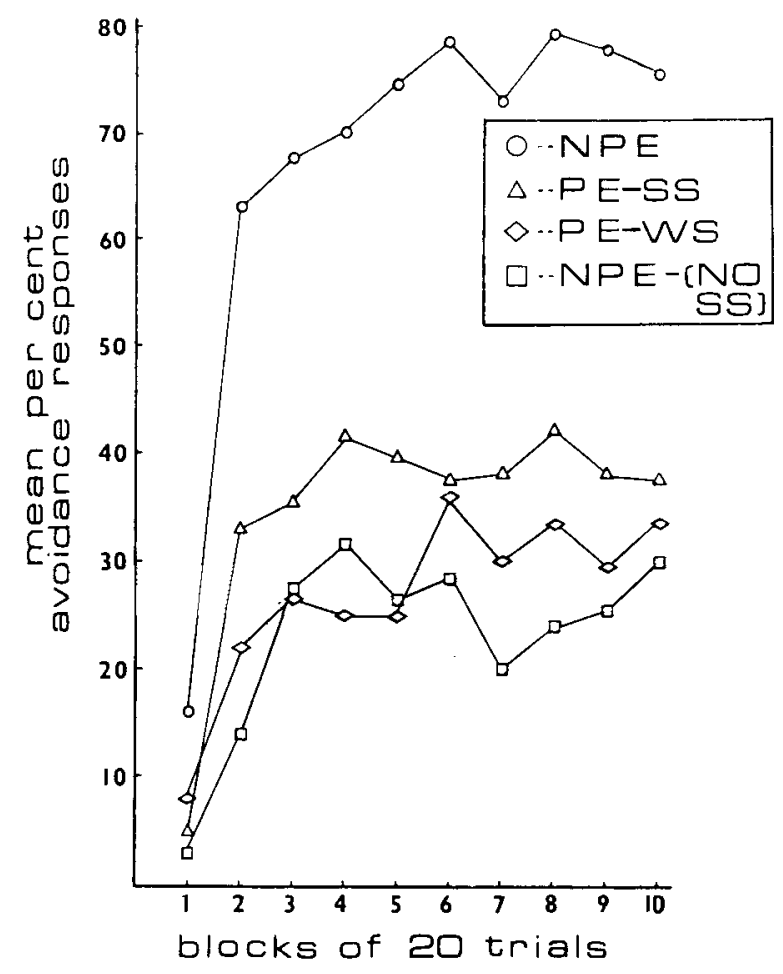

Figure 1. Mean percent avoidance responses over the 200 avoidance training trials (NPE $=$ nonpreexposed with the safety signal contingency; PE-SS = preexposed to the safety signal; PE-WS = preexposed to the warning signal; NPE (NO SS) = nonpreexposed-no safety signal contingency during avoidance conditioning).

the safety signal contingency [NPE (NO SS)] was retarded as compared to the nonpreexposed group with the safety signal contingency (NPE) over the entire 200-trial session. The mean percentage avoidance responses for each group in 200 trials were: $\mathrm{PE}-\mathrm{WS}=26.9, \mathrm{PE}-\mathrm{SS}=34.8, \mathrm{NPE}=67.5, \mathrm{NPE}$ (NO SS) $=23.1$. A one-way analysis of variance revealed significant differences between groups $[F(3,36)=7.99, p<.005]$. Newman-Keuls tests of individual comparisons showed that Group NPE made significantly more avoidance responses than Groups PE-WS $(p<.01)$, PE-SS ( $p<.01)$, and NPE (NOSS) $(p<.01)$. No other paired comparisons were significant.

A one-way analysis of variance on the number of trials to reach a criterion of eight avoidance responses in a block of 10 trials $(8 / 10)$ also revealed a significant difference between groups $[F(3,36)=$ $6.56, \mathrm{p}<.005$ ]. The mean number of trials to reach the $8 / 10$ criterion was $145.9,109.2,48.4$, and 161.6 for Groups PE-WS, PE-SS, NPE, and NPE (NO SS), respectively. Newman-Keuls comparisons showed that Group NPE reached the criterion of $8 / 10$ avoidance responses in significantly fewer trials than did Groups PE-WS $(p<.01)$, PE-SS $(p<.05)$, and NPE (NO SS) $(p<.01)$. Again, no other paired comparisons were significant.

The groups also differed in terms of the percentage of subjects per group to reach the $8 / 10$ acquisi- tion criterion. Indeed, Group NPE was the only one in which all subjects reached this criterion in the 200 -trial session. Tests of significance between two independent proportions indicated that the differences in proportion of subjects per group to reach criterion were statistically significant between Group NPE and Groups PE-WS $(z=2.58, p=.01)$, PE-SS $(z=2.24, p<.05)$, and NPE (NO SS) $(z=3.28, p<.01)$, by two-tailed tests.

\section{DISCUSSION}

In this experiment, nonpreexposed subjects learned to avoid reliably only when the safety signal contingency was in effect (Group NPE). This finding supports previous demonstrations (e.g., Bolles \& Grossen, 1969) that the presentation of a responsecontingent safety signal prevents disruption of avoidance learning when warning signal termination is delayed following avoidance responses.

In addition, the large decrement in acquisition observed in the group preexposed to the warning signal (PE-WS) upholds previous demonstrations of a robust latent inhibition effect in the two-way avoidance learning paradigm (Ackil \& Mellgren, 1968; Ackil et al., 1969). This result is predicted by both a learned-safety and a learned-irrelevance interpretation of latent inhibition.

The performance of the group preexposed to the safety signal (PE-SS) is perhaps most pertinent to the theoretical issues at hand. The retardation of avoidance acquisition observed in this group does not support an extension of learned safety which predicts that acquisition in this group should have been facilitated (or at least not retarded), since, supposedly as a result of preexposure, the safety signal enters the conditioning phase already possessing salient safety properties. This disconfirming finding is congruent with the results of recent studies which show that preexposure retards learning that the preexposed stimulus predicts the absence of aversive consequences (Best, 1975; Rescorla, 1971, Experiment 2) or the occurrence of positive reinforcement (Halgren, 1974). These findings, taken together, suggest that a learned-safety hypothesis may not be a viable explanation of the latent inhibition effect.

According to learned-irrelevance, if a stimulus receives repeated nonreinforced exposures, the subject learns to ignore it because the stimulus does not meaningfully signal reinforcement (Mackintosh, 1973). This could result in a reduction in the ability of that stimulus to form subsequent positive or negative associations. Thus, the findings that avoidance learning was retarded in both PE-WS and PE-SS groups is compatible with a learned-irrelevance view of latent inhibition (Best, 1975; Mackintosh, 1973).

In this experiment, preexposing either the WS or the SS leads to a significant decrement in the subsequent acquisition of the avoidance response. This 
result supports a learned-irrelevance hypothesis of latent inhibition but does not support a learnedsafety hypothesis. These data also suggest that learned safety may be equivalent to learned irrelevance (Best, 1975). Indeed, Kalat and Rozin (1973), themselves, entertained just such a possibility (p. 206). The results of the present study are also consistent with Rescorla's (1969) contention that in order for a stimulus to acquire safety properties it must reliably predict the absence of the unconditioned stimulus. Simply presenting a stimulus a number of times by itself does not appear to endow that stimulus with true safety properties.

\section{REFERENCES}

Ackil, J. E., \& Mellaren, R. L. Stimulus preexposure and instrumental learning. Psychonomic Science, 1968, 11, 339.

Ackil, J. E., Mellgren, R. L., Halgren, C., \& Frommer, G. P. Effects of CS preexposure on avoidance learning in rats with hippocampal lesions. Journal of Comparative and Physiological Psuchology. 1969, 69, 739.747.

BEST, M. R. Conditioned and latent inhibition in taste-aversion learning: Clarifying the role of learned safety. Journal of Experimental Psychology: Animal Behavior Processes, 1975, 1, 97-113.

Bolles, R. C., \& Grossen, N. E. Effects of an informational stimulus on the acquisition of avoidance behavior in rats. Journal of Comparative and Physiological Psychology, 1969, 68, 90-99.

HalgRen, C. R. Latent inhibition in rats. Associative or nonassociative? Journal of Comparative and Physiological Psychology, 1974, 86. 74-76.
Kalat, J. W., \& Rozin, P. "Learned safety" as a mechanism in long-delay taste aversion learning in rats. Journal of Comparative and Physiological Psychology, 1973, 83, 198-207.

Kremer, E. F. Properties of a preexposed stimulus. Psychonomic Science, 1972, 27, 45-53.

Lubow, R. E. Latent inhibition: Effects of frequency of nonreinforced preexposure to the CS. Journal of Comparative and Physiological Psychology, 1965, 60, 454-455.

Lubow, R. E. Latent inhibition. Psychological Bulletin, 1973, 79. 398-407.

Lubow, R. E., \& Moore, A. V. Latent inhibition: The effect of nonreinforced preexposure to the conditional stimulus. Journal of Comparative and Physiological Psychology, 1959, 52, 416-419.

Mackintosh, N. J. Stimulus selection: Learning to ignore stimuli that predict no change in reinforcement. In R. A. Hinde \& J. Stevenson-Hinde (Eds.), Constraints on learning. London: Academic Press, 1973.

Reiss, S., \& W AGNER, A. R. CS habituation produces a "latent inhibition effect" but no active "conditioned inhibition." Learning and Motivation, 1972, 3. 237-245.

Rescorla, R. A. Pavlovian conditioned inhibition. Psychological Bulletin, 1969, 72, 77-94.

Rescorla, R. A. Summation and retardation tests of latent inhibition. Journal of Comparative and Physiological Psychology, 1971, 75, 77-81.

SIEgEL, S. Effect of CS habituation on eyelid conditioning. Journal of Comparative and Physiological Psychology, 1969, 68, 245-248.

SIEGEL, S. Flavor preexposure and "learned safety." Journal of Comparative and Physiological Psychology. 1974, 87, 1073-1082.

(Received for publication October 7, 1975; revision received September 16. 1976.) 